\title{
The influence of coating damage on the impressed current cathodic protection effect
}

\author{
J. Wu ${ }^{1,2}$, S. Xing ${ }^{1,2} \&$ F. Yun ${ }^{1,2}$ \\ ${ }^{1}$ State Key Laboratory for Marine Corrosion and Protection, PR China \\ ${ }^{2}$ Luoyang Ship Material Research Institute, PR China
}

\begin{abstract}
A one-hundredth scale hull model in linear scaled resistivity was used to simulate the cathodic protection potential distribution of a hull with different coating damage extent and position. The potential distribution of the hull was simultaneously measured by a PXI modular instrument and a program written in Labview 7.1. At the same time the potential and current density of the vessel with a $2 \%, 4 \%$ and $6 \%$ damage were calculated by the boundary element method. The results obtained from the physical scale model (PSM) method agreed with calculation results. The impressed current cathodic protection (ICCP) effect and its induced electric signature were simultaneously influenced by the coating damage extent and position. The damage extent mainly influenced the ICCP output current and $x$ axis's electric signature and the damage position mainly influenced the electric signature of the $y$ axis. The calculation results showed that the electric signature increased by about $35.7 \%$ due to $6 \%$ coating damage.
\end{abstract}

Keywords: cathodic protection, physical scale model, computer simulation, electric signature.

\section{Introduction}

Corrosion damage is a major factor in ship maintenance and availability. Coating combined with an impressed current cathodic protection (ICCP) system is the most common means of shipboard corrosion control. The two methods interact with each other to protect the shipboard. Coatings provide primary corrosion protection by isolating the hull metal from the seawater, while ICCP systems protect the hull by applying an external source of current to the ship where the paint is damaged or degraded. 
The cathodic protective effect is related to the ICCP design and coating state. Before 1980s, the effect of an ICCP system, designed by experience, could not be exactly known. In the past decade, considerable effort has been spent on the development of the rapid estimate and design methodologies which have a scientific rather than designer expertise basis. Two such methodologies are the physical scale model (PSM) method and computational modeling using boundary element techniques [1].

The PSM technique has been developed to assess the performance of ICCP systems installed on shipboards since 1980s. It has been reported that directly proportional dilution of the seawater results in a similar potential with reference to miniature electrodes placed along the side of the model as the actual potential on a full-size ship [2]. Apart from evaluation, this technique could help in examining the relationships between the coating state and ICCP protection effect and optimize the position of anodes and reference electrodes initially; thus, it has been used to design ICCP systems installed on US Navy ships. But the PSM involves only physical scale not chemical scale, so it is impossible to overcome the change in polarization behavior in a scaled resistivity electrolyte [3]. In recent years, computer simulation technology has been developed for calculating potential and current density distribution in electrochemical systems. A computer simulation technique can rapidly yield the potential and current density distribution on the hull with different coating state to estimate the impact of coating damage extent and position on an ICCP system. A primary limitation of computer simulation is the need for accurate and appropriate polarization response data [4], while the PSM does not require polarization response data. The concept of a unified approach between computational simulation and PSM is very attractive since it uses the strengths of each method to compensate for the weaknesses of the other [4]. The unified approach uses validated computational tools to examine hull geometry, boundary conditions and other parameters to define a relatively small set of experiments that can be completed in a time and cost efficient manner.

According to experience, coating state plays an important role in the distribution of cathodic protective potential and electric signature, but there were few reports about how the coating damage influences the potential and signature distribution. In order to control the signatures and to preserve the integrity of a vessel it is essential to predict the impact of coating damage extent and position on the electric fields and potential distribution. In this paper, PSM and boundary element method (BEM) technologies (BEASY10.0) were used to study the coating damage influence on protective potential and electromagnetic signature.

\section{Experimental work}

\subsection{Physical scale model}

A vessel with a length of $125 \mathrm{~m}$ was investigated. The ship had 250 frames at intervals of $0.5 \mathrm{~m}$ and the frames were designated 0 to 250 from bow to stern. The ship scale model was a one/hundredth scale hull model with the same materials as 
the actual ship and the model was immersed in seawater diluted to the same scale ratio. The scale model is shown in Fig. 1. The definition of coating damaged position and area shown in Table 1 was based on observations of ships in dry-dock after a period of service time. Throughout, the tests were performed at room temperature, potential measurements were made with eight $\mathrm{Ag} / \mathrm{AgCl}$ reference electrode fitted with Luggin capillaries.

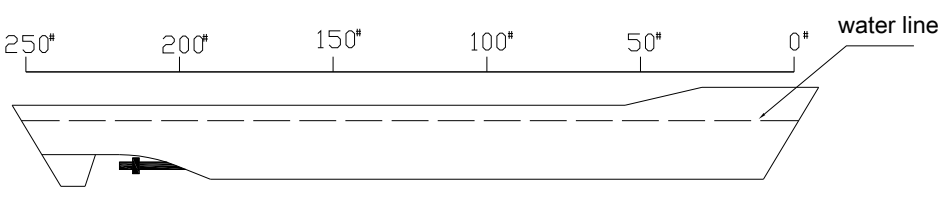

Figure 1: Physical scale model of vessel.

Table 1: Shipboard coating damage extent and position.

\begin{tabular}{cccc}
\hline Coating state & $2 \%$ damage & $4 \%$ damage & $6 \%$ damage \\
\hline \multirow{2}{*}{ Damage position } & $50^{\text {th }}$ frame & $120^{\text {th }}$ and $200^{\text {th }}$ frame & $50^{\text {th }}, 120^{\text {th }}$ and \\
& $($ symmetrical) & (symmetrical) & $200^{\text {th }}$ frame \\
(symmetrical)
\end{tabular}

\subsection{Measurement system}

The protective potential of different positions on vessel was simultaneously gathered by National Instruments and Labview 7.1 program.

\subsection{Potential measurements}

The scale model was immersed in sea water hold in a tank with dimensions $1.8 \mathrm{~m} \times 0.6 \mathrm{~m} \times 0.9 \mathrm{~m}$ and polarized to $-850 \mathrm{mV}$ for two days for the formation of calcium and magnesium deposition, then the model was moved into diluted sea water with the conductance of $379 \mu \mathrm{S} / \mathrm{cm}$. The potential of $10^{\text {th }}, 30^{\text {th }}, 50^{\text {th }}, 70^{\text {th }}$, $90^{\text {th }}, 110^{\text {th }}, 130^{\text {th }}, 150^{\text {th }}, 170^{\text {th }}, 190^{\text {th }}, 210^{\text {th }}, 230^{\text {th }}$ and $250^{\text {th }}$ frame was measured with the reference electrode potential set at $-850 \mathrm{mV}$.

\subsection{Computer simulation}

The ship has two propellers and two rudders. The propellers were made of a nickel-aluminium-bronze alloy (NAB) and modeled as solid disks with equivalent surface area as the real propellers. The shaft was made of carbon steel and the propellers and shafts were assumed to be uncoated because of turbulence engendered by propeller movement. The ship hull and rudders were also made of carbon steel and they were coated to prevent corrosion. The ICCP system evaluated included four anodes and a centre controlled power supply. The BEM model of half of the ship is shown in Fig. 2. 
The cathodic polarization curves of uncoated and coated carbon steel are shown in Fig. 3(a) and the polarization curve of NAB is shown in Fig. 3(b); these were set as the boundary conditions of the ship model.

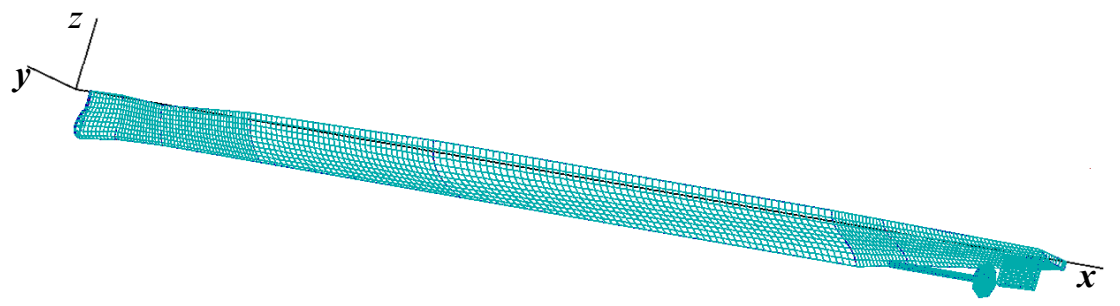

Figure 2: BEM model of ship.

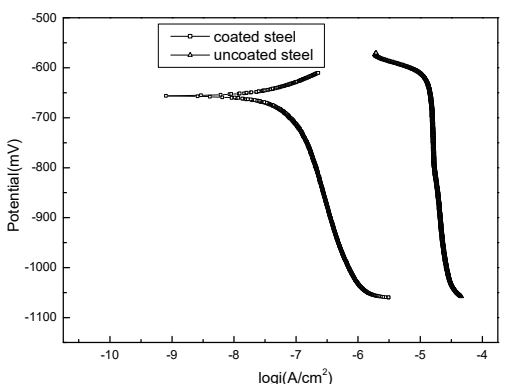

(a) Carbon steel

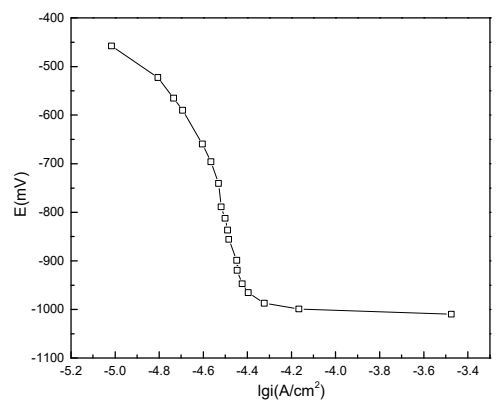

(b) NAB

Figure 3: Boundary conditions.

\section{Results and discussion}

\subsection{Potential simulation}

Former studies indicated that the ICCP system would perform best when the anodes are symmetrically installed at the $130^{\text {th }}$ and the $232^{\text {nd }}$ frames and the reference electrode is installed at the $186^{\text {th }}$ frame. The hull of ship was under sufficient protection when the coating was intact, as shown in Fig. 4. The PSM measured data and computational results agreed well with each other except in the anode zones. The difference between PSM and BEM in the anode zones was most likely due to the change in polarization of the materials in the diluted seawater, because the PSM supposes that dilution of the electrolyte does not significantly change the polarization behavior of the materials [5].

When the coating was symmetrically damaged at the $50^{\text {th }}$ frame and the damage area was about $2 \%$ of the whole underwater area, the potential distribution 
measured by experimental PSM and calculated by computer simulation is shown in Fig. 5. According to PSM experimental results and calculation data, the ICCP system can still provide enough cathodic protection to the hull with the potential ranging from $-800 \mathrm{mV}$ to $-1100 \mathrm{mV}$ with the reference electrode reading of $-850 \mathrm{mV}$. Because of the coating damage and damage positions being far away from the anodes, the potential at coating damage positions changed more positive in comparison with the area elsewhere.

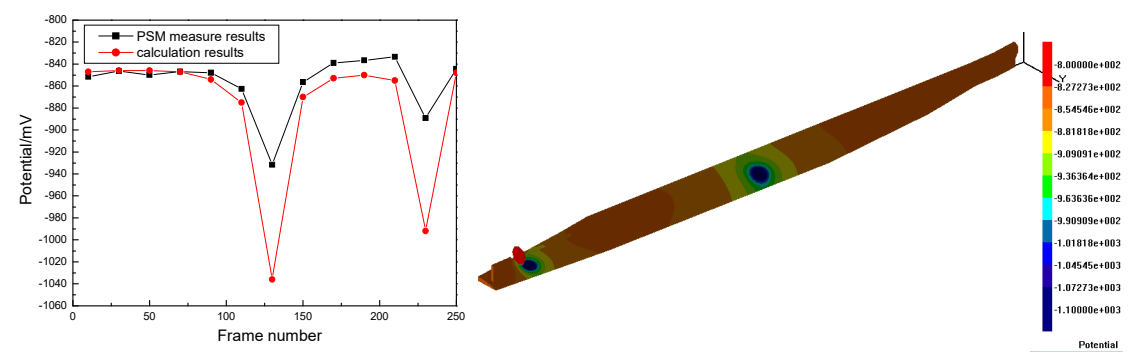

Figure 4: The potential $(\mathrm{mV})$ distribution of ship hull when coating perfect.
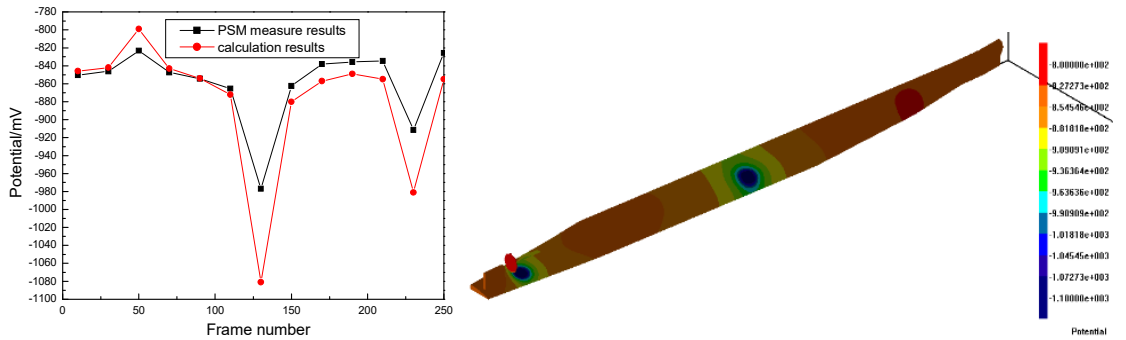

Figure 5: The potential $(\mathrm{mV})$ distribution of ship hull when coating $2 \%$ damage.

Even though the coating damage area increased, it had a small influence on the potential distribution, as shown in Fig. 6. The hull was under protected and there was no potential wave in the coating damage regions. According to ohm law, the resistance is directly proportional to length, so if the coating damage position was neighboring the anode, the potential of the uncoated steel could be easily polarized to the designed level even though the uncoated steel consumed more current than the coated steel.

Similarly, the coating was symmetrically damaged at the $50^{\text {th }}, 120^{\text {th }}$ and $200^{\text {th }}$ frames and the damage area was the same at each location; the potential variation at the $50^{\text {th }}$ frame was the biggest among the coating damage regions as shown in Fig. 7. So for the ICCP system, when the coating damage extent was less than $6 \%$, the protective potential was mainly influenced by the coating damage position, not the damage area. 


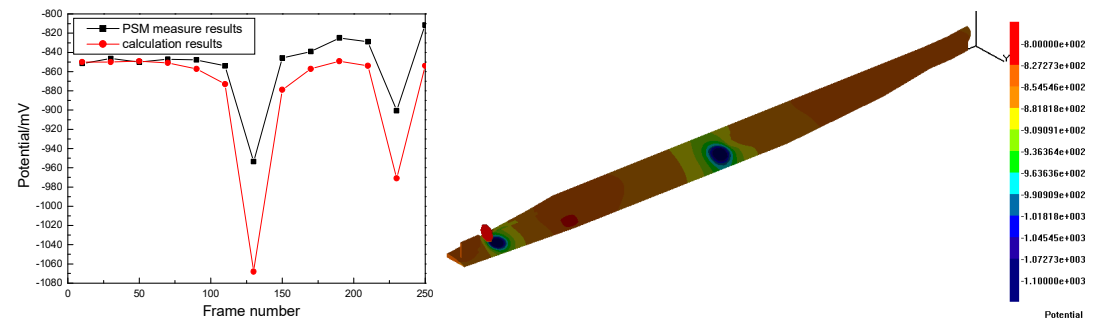

Figure 6: The potential $(\mathrm{mV})$ distribution of ship hull when coating 4\% damage.

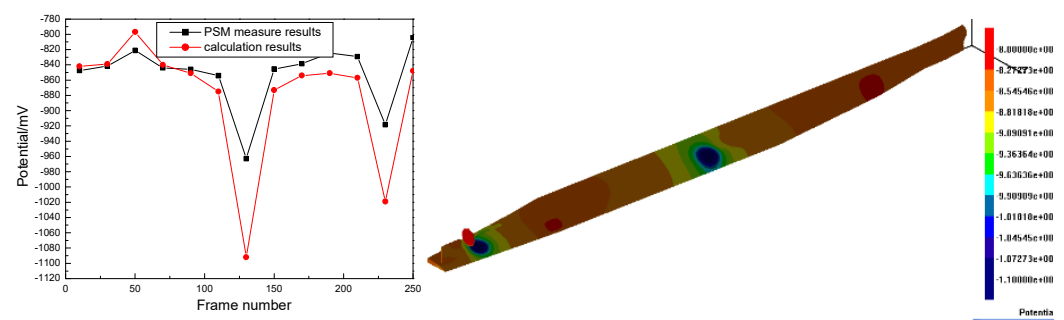

Figure 7: The potential $(\mathrm{mV})$ distribution of ship hull when coating $6 \%$ damage.

\subsection{Electromagnetic signature simulation}

A line of sampling points was defined at a depth of $10 \mathrm{~m}$ beneath the sea level, and the vertical distance between simulation points and keel was about $10 \mathrm{~m}$. The solution at the sampling points along this line was used to compute the electric signature. The underwater potential is shown in Fig. 8 and the current density along $x, y$ and $z$ axis is shown in Fig. 9. According to the calculation results, the potential gradient nearby the anodes increased with the coatings damage increase and the electric signature increased by about $35.7 \%$ when the coating was $6 \%$ damaged compared with the perfect coating. Due to the coating damage positions far away from anodes, the coating damage of $50^{\text {th }}$ frame resulted in potential gradient increase in the bow region.

It is well known that the polarization current of uncoated steel is obviously larger than that of coated steel. So, if some regions' coating of hull is damaged, the ICCP system must increase the output current to maintain the hull potential under the critical potential, and then the total output current increases with damage extent increase. But the current density distribution along $x, y$ and $z$ axis at the same time was influenced by the damage position. From Fig. 9, it can be seen that, the $x$ axis's current density was mainly influenced by the damage extent, the current density along $y$ axis was mainly influenced by the damage position and the $z$ axis's current density was influenced by both damage extent and position. That is to say, the coating damage extent may result in the electric signature increase along the vessel and the bow's coating damage may induce the electric signature to increase in the vertical orientation. 


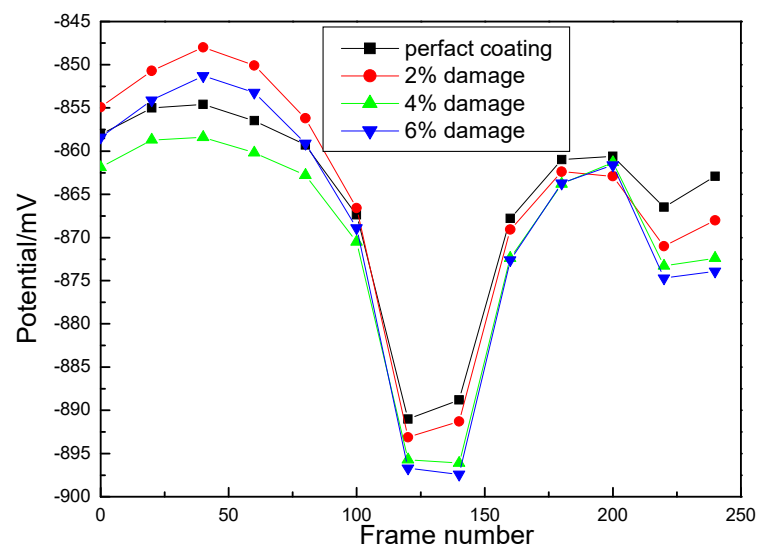

Figure 8: Underwater potential distribution along the keel.

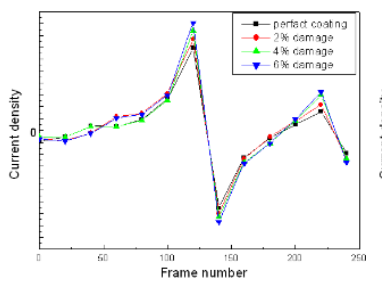

(a) $x$ axis

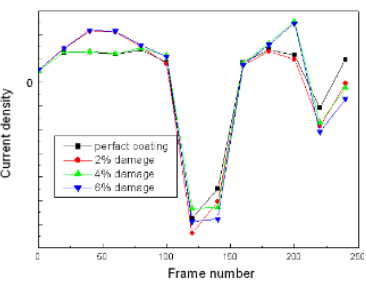

(b) $y$ axis

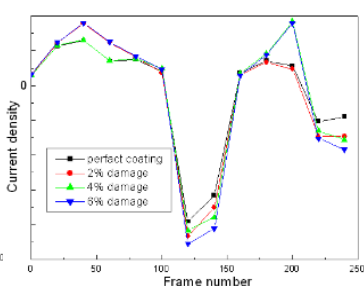

(c) $z$ axis

Figure 9: Current density distribution along the keel.

\section{Conclusions}

According to the PSM and computer simulation studies, the ICCP protection effect and its induced electric signature were simultaneously influenced by the coating damage extent and position. The potential gradient and the electric signature increased with the increase of coating damage area and the electric signature increased by about $35.7 \%$ when the coating damage area extended by $6 \%$. The damage extent mainly influenced the ICCP output current and $x$ axis's electric signature and the damage position mainly influenced the electric signature of the $y$ axis.

\section{References}

[1] DeGiorgi, V.G, Thomas, E.D, Lucas, K.E. \& Kee, A., A combined design methodology for impressed current cathodic protection systems. WIT Transactions on Modelling and Simulation, 15, pp. 335-345, 1996. 
[2] Ditchfield, R.W., McGrath, J.N. \& Tighe-Ford, D.J., Theoretical validation of the physical scale modelling of the electrical potential characteristics of marine impressed current cathodic protection. Journal of Applied Electrochemistry, 25, pp. 54-60, 1995.

[3] Gurrappa, I., Physical and computer modeling for ship's impressed-current cathodic-protection systems. Corrosion Prevention and Control, 41(2), pp. 40-45, 1994.

[4] DeGiorgi, V.G., Wimmer, S.A., Hogan, E. \& Lucas, K.E., Modeling the experimental environment for shipboard ICCP systems. WIT Transactions on Modelling and Simulation, 32, pp. 439-447, 2002.

[5] Gage, N. \& Mart, P., Further cathodic protection studies of naval ships [J], CAP, pp. 1-13, 2002. 